\title{
Can Fighting Grade Inflation Help the Bottom Line?
}

\author{
Arthur J. Caplan ${ }^{*}$ \\ Associate Professor \\ Department of Applied Economics \\ Utah State University \\ John Gilbert \\ Associate Professor \\ Department of Economics and Finance \\ Utah State University
}

\begin{abstract}
This paper uses a rich set of student transcript data to estimate the economic cost incurred by a university when it does not adopt a 'mean-shift grading policy' to fight grade inflation. We show that even in the face of moral hazard constraints a university can enhance its profitability by fighting grade inflation with a distributionshifting policy.
\end{abstract}

Keywords: grade inflation, mean-shift grading policy, economic cost

JEL: D21, D61, I20

Running Head: Grade Inflation and the Bottom Line

* Corresponding author. Address Correspondence to: Arthur Caplan, Department of Applied Economics, Utah State University, 3530 Old Main Hill, Logan, UT 84322-3530. Ph: 435-797-0775. FAX: 435-797-2701. E-mail: arthur.caplan@usu.edu. 


\section{Introduction}

The on-going debate over grade inflation is focused on whether instructors have been too generous in awarding their students high grades over the past 25 years, inflating cumulative grade point averages (see Johnson, 2003, and Kohn, 2004). The debate has left unanswered two interrelated questions. Should we truncate the grade distribution's upper end (as Princeton is doing) or adjust the mean grade toward the distribution's lower end (which would shift the entire distribution, resulting in fewer A's and more F's)? Assuming this latter type of 'mean-shift grading policy' is warranted, what would the effect be on an institution's revenues? To answer these questions, we develop a theoretical profitability benchmark (Section 2). We then use a rich set of student transcript data to estimate the four-year economic cost associated with non-implementation (Section 3). Section 4 concludes.

\section{Theoretical Benchmark}

Consider an academic institution that chooses the number of courses typical students of class-standing $i$ majoring in a discipline in each of $j$ colleges fails during the periods $t$ of their degree programs, $F_{i j t}$. This counterfactual problem may be written as,

$\max _{F_{i j t}} \int_{t=0}^{\infty}\left[\sum_{i=1}^{I} \sum_{j=1}^{J}\left\{T_{t}^{F} F_{i j t}-P_{i j t}\left(F_{i j t}\right) T_{i t}^{C D}\right\}+\phi S_{t}-H\left(F_{i j t}\right)\right] e^{-\rho t} d t, i=1, \ldots, I, j=1, \ldots, J$

subject to

$S_{t}=\bar{S}-\sum_{j=1}^{J} \alpha_{j} C_{j}\left(\sum_{i=1}^{I} F_{i j t}\right) \geq 0, i=1, \ldots, I\left(F_{i j t}\right), j=1, \ldots, J$

where $T_{t}^{F}$ is the per-course tuition rate (invariant across student types and colleges) in period $t$; $T_{i t}^{C D}=\int_{t}^{t+T_{i}} T_{t}^{D} e^{-\rho t} d t$ is the discounted cumulative tuition revenue lost for student type $i$ from period $t$ onward ( $T_{t}^{D}$ is tuition revenue lost during period $t$ and $T_{i}$ is the finite number of periods 
during which tuition revenue is lost); $P_{i j t}\left(F_{i j t}\right)$ is student $i$ 's (in college $j$ ) probability of dropping out of the university $P_{i j t}^{\prime}>0, P_{i j t}^{\prime \prime} \geq 0, \forall i, j$ and $t ; \rho>0$ is a discount rate; $S_{t}>0, \bar{S}>0$, and $C_{j}$ are, respectively, current unutilized institutional capacity, steady-state (or, historical) unutilized institutional capacity, and additional utilized capacity at college $j^{\prime}$ s level $\left(C_{j}^{\prime}>0, C_{j}^{\prime \prime} \geq 0, \forall j\right) ; \phi$ is the per-unit value of unutilized institutional capacity (measured as implicit net revenue); and $0<\alpha_{j}<1$ is a college-level capacity weighting factor, $\sum_{j=1}^{J} \alpha_{j}=1 .{ }^{1}$ Lastly, the expected-value function $H\left(F_{i j t}\right)$ accounts for potential moral hazard effects $\left(H^{\prime}>0, H^{\prime \prime} \geq 0\right)$. Whereas the derivatives of the functions $P_{i j t}\left(F_{i j t}\right)$ and $C_{j}\left(\sum_{i=1}^{I} F_{i j t}\right)$ represent marginal effects, the derivative of $H\left(F_{i j t}\right)$ represents an inframarginal effect. $^{2}$

Assuming an interior solution, the necessary conditions for this problem are capacity constraint (1) and (dropping the $t$ subscript for convenience),

$T^{F}=E M C_{i j}=P_{i j}^{\prime}\left(F_{i j}\right) T_{i}^{C D}+\alpha_{j} \phi C_{j}^{\prime}\left(\sum_{i=1}^{I} F_{i j}\right)+H_{i j}^{\prime}, \quad \forall i, j$

Conditions (2) are the decision rules determining $F_{i j}^{*}, i=1, \ldots, I, j=1, \ldots, J$. In this case, $T^{F}$ represents marginal revenue from an additional failed course by student $i$ in college $j$ and $E M C_{i j}$ represents the associated expected marginal cost. The first marginal effect in $E M C_{i j}\left(P_{i j}^{\prime}\left(F_{i j}\right) T_{i}^{C D}>0\right)$ accounts for the expected cost associated with lost cumulative future tuition revenue due to an increased probability that the student will drop out. The second term $\left(\alpha_{j} \phi C_{j}^{\prime}\left(\sum_{i=1}^{I} F_{i j}\right)>0\right)$ represents the marginal effect associated with reduced unutilized institutional capacity. The third term $\left(H_{i j}^{\prime}\right)$ accounts for an expected inframarginal "net" moral hazard effect. This effect is comprised of two components. The first, which is positive, represents the moral hazard effect of an additional failing grade for student $i$ in college $j$. The second represents the effect of an additional failing grade for student $i$ on the institution's excess capacity. This is negative, since a reduction in the cohort of incoming students works to relieve the excess-capacity constraint. ${ }^{3}$ 
Optimality conditions (2) may therefore be rewritten more succinctly as (with subscript $j$ now dropped for further convenience),

$T^{F}=E M C_{i k}=\left(1-\beta_{k}\right) P_{i}^{\prime}\left(F_{i}\right) T_{i}^{C D}+H_{i j}^{\prime}, i=1, \ldots, I$

where $\beta_{k}>0$ is the percentage increase in expected marginal cost due to the effect of reduced unutilized capacity, $k=\{$ low, moderate, high $\}$. For simplicity we assume that $\beta_{k}$ and $H^{\prime}\left(F_{i}\right)$ are both constant across colleges. Conditions (3) illuminate our main empirical problem. If $F_{i}^{*}$ can be estimated, it can be compared with the actual number of courses the typical student fails to determine the extent to which a mean-shift grading policy might enhance an institution's profitability.

\section{Empirical Results}

To estimate $F_{i}^{*}$, transcript data for 22,000 undergraduate and graduate students were obtained from Utah State University based on a sample frame of all students who had declared a major in the College of Business (COB) either prior to or during the period 1995-2004, regardless of whether the student ultimately graduated with that or another COB major, and who was either still enrolled during that period or had graduated or dropped out. Students who were still enrolled, who transferred out of COB to a different college, were graduate students, or for whom we had missing data, were dropped from the sample. Our final sample size was approximately 12,500 undergraduate students. Table 1 includes the definitions and summary statistics for the variables used.

To determine $F_{i}^{*}$ a LIML procedure is used to jointly estimate $P_{i}^{\prime}(\operatorname{Pr}(\mathrm{DROP}=1))$ and \#FAIL (Greene, 2003). Joint estimation is required because of the potential for endogeneity that exists between these two variables. ${ }^{4}$

In the first step we estimate $\operatorname{Pr}\left(\# \mathrm{FAIL} \mid \mathbf{X}_{\mathbf{1}}\right)$, where each student's \#FAIL is drawn from a zero-inflated negative-binomial distribution in order to account for the count nature of the data, with mean over-dispersion and a preponderance of zeros (i.e., students who have not failed any courses). ${ }^{5}$ 
The covariate vector $\mathbf{X}_{\mathbf{1}}$ includes a subset of the variables in Table $1 .^{6}$ From the estimation of $\operatorname{Pr}\left(\# \mathrm{FAIL} \mid \mathbf{X}_{\mathbf{1}}\right)$ we obtain vectors of predicted values for \#FAIL and \#FAIL ${ }^{2}$ (henceforth $\hat{F}$ and $\hat{F}^{2}$ ), which are used as covariates in the second-step estimation of the probability of dropping out. Here, we estimate $\operatorname{Pr}\left(\mathrm{DROP}=1 \mid \mathbf{X}_{2}\right)$ assuming a standard normal (probit) distribution conditioned on covariate vector $\mathbf{X}_{2}$ with robust standard errors (White, 1980). To correct for potential generatedregressor bias in this second-step regression we perform a series of 500 bootstrapped regressions for both steps one and two in order to recover non-parametric estimates of the standard errors in step two (Efron and Tibshirani, 1993; Stine, 1990).

Table 2 reports the estimated marginal effects for $\operatorname{Pr}\left(\mathrm{DROP}=1 \mid \mathbf{X}_{2}\right)$. On average, older students are more likely to drop out than younger students. Men, married students, and students with higher GPAs are less likely to drop out. The positive effect of INTERACT $(=$ FAIL $\times$ GPA) indicates that the negative effect of GPA on DROP is less for those students who have failed at least one course. The marginal effects of $\hat{F}$ and $\hat{F}^{2}$ on $\operatorname{Pr}(\mathrm{DROP}=1)$ denote an upward-sloping EMC curve. Finally, the goodness-of-fit measures, $\Omega_{1}$ and $\Omega_{2}$, indicate that the model correctly predicts 78 and 85 percent, respectively, of those students who dropped out and those who graduated. These measures tally as a correct prediction any predicted value that is within a magnitude of 0.5 of its corresponding DROP value.

To determine $F_{i}^{*}$, the marginal effects for $\mathbf{X}_{2}$ are combined with 2004-2005 tuition data obtained from the USU Budget Office. ${ }^{7}$ Tuition costs per three-credit course are estimated to be $\$ 421$ and \$1,212 for resident and non-resident students, respectively. ${ }^{8}$ The USU Budget Office also reports annual tuition costs of approximately $\$ 3,330$ and $\$ 9,700$ per year (two semesters), respectively. For simplicity, we assume that the decision to drop out is made with two years remaining to complete the degree program. Based on the yearly tuition costs cited above, the (discounted weighted-average) cumulative tuition foregone to the university when students decide to drop out is approximately $\$ 8,796$. Assuming that the percentages of freshman, sophomores, juniors, and seniors at any given time are each 25 percent, the average cumulative tuition foregone is therefore $\$ 7,713 .{ }^{9}$ Finally, to 
account for the possibility of added costs associated with a reduction in excess capacity as students fail more courses (i.e., $\beta_{k}$ in equation 3), we set $\beta_{\text {low }}=0, \beta_{\text {moderate }}=1$, and $\beta_{\text {high }}=2$.

The EMC for the average student is calculated by applying the estimated marginal effects to the corresponding mean values of the variables included in $\mathbf{X}_{2}$ (excluding $\widehat{F}$ and $\hat{F}^{2}$ ). Note that the 'naïve' (i.e., potential moral hazard ignored) number of failed courses for the average student at $\beta_{\text {low }}$ is approximately nine, implying a per-student economic cost (over the course of an undergraduate student's four-year degree program) of roughly $\$ 4,600$. Due to the near verticality of the EMC curve in the neighborhood of the marginal revenue curve, $\mathrm{T}^{\mathrm{F}}$, the naïve number of failed courses and corresponding economic costs for $\beta_{\text {moderate }}$ and $\beta_{\text {high }}$ effectively remain unchanged vis-à-vis $\beta_{\text {low }}$. Thus, based on our assumption of marginal reductions in unutilized capacity, as students fail more courses, the naive number of failed courses and corresponding economic costs do not shrink in the presence of reductions in unutilized capacity.

Lastly, we ask how large (in cost per student and per failed course) would moral hazard have to be in order to reduce by half the profit-maximizing number of failed courses? In other words, we back-out what size the effect would have to be in order to reduce the profit-maximizing number of failed courses for the average student from nine to four. We find that a reduction in the profitmaximizing number of failed courses from nine to four corresponds to net moral hazard valued at approximately $\$ 2,300$ per student, or $\$ 575$ per failed course above four. If this inframarginal shift in EMC accurately reflects the extent of net moral hazard associated with failing more students at a given institution, then the optimal number of courses the typical student should fail over a four-year period would instead be four, with a corresponding economic cost of approximately $\$ 2,300$ per student (based on the 0.97 courses that the typical student currently fails).

\section{Conclusion}

This paper has provided an initial answer to the following question. If the academic profession begins to fight grade inflation (e.g., through the adoption of a mean-shift grading policy), would 
administration need to be concerned about the effect on the institution's "bottom-line?" Our results suggest that the answer to this question is "no." In concert with a shift in the grade distribution there is scope for the typical student to fail more courses over the course of their academic career, resulting in recovery of as much as $\$ 4,600$ in economic costs per student in a 'naïve' scenario (where potential moral hazard problems are ignored or perceived as non-binding). Future research should focus on the potential effect of moral hazard on this type of estimate, in particular the effect of demand-side moral hazard.

\section{Acknowledgments}

Thanks to Glenn Davis, Utah State University (USU) Registrar, and Caryn Beck-Dudley, Former Dean of the USU College of Business, for granting access to the student transcript data used in this study, and Randy Shelton and Krystin Deschamps for compiling the data. Prithvi Jutur was instrumental in writing the Excel macros that further compiled the data into the dataset used for this study. We also greatly benefitted from discussions with colleagues David Dickinson and David Aadland; discussions that ultimately provoked us to write this paper. 


\section{References}

Chiang, A.C. (1992) Fundamental Methods of Mathematical Economics, Third Edition. New York, McGraw-Hill.

Efron, B. and R. Tibshirani. (1993) An Introduction to the Bootstrap, New York, Chapman and Hall.

Greene, W.H. (2003) Econometric Analysis, Fifth Edition, Singapore, Pearson.

Johnson, V.E. (2003) Grade Inflation: A Crisis in College Education, New York, Springer.

Kohn, A. (2004) What Does it Mean to be Well Educated? And More Essays on Standards, Grading, and Other Follies, Boston, Beacon Press.

Long, J.S. (1997) Regression Models for Categorical and Limited Dependent Variables, Thousand Oaks, Sage Publications.

Stine, R. (1990) An introduction to bootstrap methods: examples and ideas, in Modern Methods of Data Analysis, ed. J. Fox and J.S. Long. Newbury Park, Sage Publications.

Vuong, Q. (1989) Likelihood ratio tests for model selection and non-nested hypotheses, Econometrica, 57, 307-34.

White, H. (1980) A heteroscedasticity-consistent covariance matrix estimator and a direct test for heteroscedasticity, Econometrica, 48, 817-38.

Wu, D. (1973) Alternative tests of independence between stochastic regressors and disturbances, Econometrica, 41, 733-50. 
Table 1: Variable Definitions

\begin{tabular}{llc}
\hline Variable & Description & Mean (SD) \\
\hline ENTER & Year student first enrolled $(21=2004, \ldots \ldots, 1=1983)$. & $13.40(2.40)$ \\
DROP & $1=$ dropped out, $0=$ graduated. & $0.46(0.50)$ \\
AGE & Age (in years) when first enrolled. & $29.53(7.13)$ \\
GENDER & $1=$ male, $0=$ female. & $0.60(0.49)$ \\
MARITAL & $1=$ married, $0=$ single. & $0.31(0.46)$ \\
ETHNIC1 & $1=$ international student, $0=$ otherwise. & $0.08(0.28)$ \\
ETHNIC2 & $1=$ Asian student, $0=$ otherwise. & $0.01(0.11)$ \\
ETHNIC3 & $1=$ U.S. white student, 0 = otherwise. & $0.88(0.33)$ \\
\#COURSES & Total number of different courses taken during degree & $30.03(18.95)$ \\
& program. & \\
FAIL? & Did student fail at least one course during degree & $0.38(0.49)$ \\
\#FAIL & $\begin{array}{l}\text { program? } 1=\text { yes, } 0=\text { no. } \\
\text { Total number of courses failed during degree program. }\end{array}$ & $0.97(1.91)$ \\
GPA & Cumulative GPA (if FAIL? = 0), Cumulative GPA up & $2.98(0.56)$ \\
RETAKE & to first failed course (if FAIL? = 1) (4.0 is maximum). & $1.79(3.07)$ \\
\hline
\end{tabular}


Table 2: Probit Regression Results for $\operatorname{Pr}\left(\mathrm{DROP}=1 \mid \mathrm{X}_{2}\right)$

\begin{tabular}{|c|c|}
\hline Explanatory Variable & $\begin{array}{l}\text { Marginal Effects } \\
\text { (Standard Error) }\end{array}$ \\
\hline ENTER & $\begin{array}{c}-0.0839 * * * \\
(0.0014)\end{array}$ \\
\hline AGE & $\begin{array}{c}0.0101 * * * \\
(0.0038)\end{array}$ \\
\hline GENDER & $\begin{array}{l}-0.0777^{*} \\
(0.0533)\end{array}$ \\
\hline MARITAL & $\begin{array}{c}-0.1911 * * * \\
(0.0413)\end{array}$ \\
\hline ETHNIC1 & $\begin{array}{c}-0.2905^{* * *} \\
(0.0889)\end{array}$ \\
\hline ETHNIC2 & $\begin{array}{c}0.1514 \\
(0.2121)\end{array}$ \\
\hline ETHNIC3 & $\begin{array}{c}-0.2990 * * \\
(0.1354)\end{array}$ \\
\hline GPA & $\begin{array}{c}-1.1853 * * * \\
(0.0409)\end{array}$ \\
\hline INTERACT & $\begin{array}{c}0.1109 * * * \\
(0.0021)\end{array}$ \\
\hline$\hat{F}^{\mathrm{b}}$ & $\begin{array}{c}-1.5714 * * * \\
(0.1439)\end{array}$ \\
\hline$\hat{F}^{2}$ & $\begin{array}{c}0.1770 * * * \\
(0.0352)\end{array}$ \\
\hline Log likelihood & $-1,806.30$ \\
\hline$\chi^{2}(\mathrm{LR})$ & $2,589.41^{* * *}$ \\
\hline Pseudo $\mathrm{R}^{2}$ & 0.42 \\
\hline Number of Observations & $4,505^{\mathrm{a}}$ \\
\hline$\Omega_{1}=\frac{\text { Predicted Drop }=1}{\text { Observed Drop }=1}$ & 0.78 \\
\hline$\Omega_{2}=\frac{\text { Predicted Drop }=0}{\text { Observed Drop }=0}$ & 0.85 \\
\hline
\end{tabular}

*** Significant at $1 \%$ level, ** Significant at $5 \%$ level, * Significant at $10 \%$ level.

${ }^{a}$ The number of observations are restricted by the sample size in the first-stage regression.

${ }^{\mathrm{b}} \hat{F}$ is \#FAIL and $\hat{F}^{2}$ is (\#FAIL) ${ }^{2}$. 


\section{Notes}

${ }^{1} \phi$, which is purposefully unsigned, accounts for the relative sizes of the benefits (e.g., reduced bottlenecks) and costs (e.g., vacant classrooms on campus) of unutilized institutional capacity. Appropriate curvature and bounding conditions on the profit function ensure that the integral in the objective function converges (Chiang, 1992).

${ }^{2}$ We assume the possibility of both demand-side moral hazard (e.g., reduced demand exhibited by potential incoming students, strategic behavior by the institution's competitors) and supply-side moral hazard (e.g., excessive use of failing grades by certain faculty members, strategic behavior among departments within the institution). Although estimating the potential effects of demand-side moral hazard on an institution's longer-term profitability is beyond the scope of this paper, we are able to illustrate how large the effects would have to be in order to reduce by half the 'naïve' fail rate, i.e., the profit-maximizing number of failed courses when demand-side moral hazard is ignored.

${ }^{3}$ Similar to potential moral hazard, the effect of reduced unutilized capacity on $F_{i j}^{*}$ cannot be determined empirically due to data limitations. We consider three numerical scenarios to capture the sensitivity of $F_{i j}^{*}$ to various degrees of reduction.

${ }^{4}$ We conducted a Hausman test for joint determination following the method originally proposed by $\mathrm{Wu}$ (1973). The results, available from the authors upon request, indicate that DROP and \#FAIL are jointly determined at the $1 \%$ level of significance.

${ }^{5}$ The zero-inflation model follows Long (1997, pgs. 242-247), Greene (2003), and Vuong (1989).

${ }^{6}$ The results from this first-step regression are available from the authors upon request.

${ }^{7}$ Further information is available on request.

${ }^{8}$ These figures are based on a typical student enrolling for four three-credit courses per semester. The university reports that approximately 80 percent of the incoming freshmen for 2004-2005 were residents. Therefore, the weighted average of the resident and non-resident tuition per-course tuition cost is approximately $\$ 580$.

${ }^{9}$ We assume a 3 percent discount rate. 